\title{
EFEITO DE NÍVEIS DE ÁGUA, COBERTURAS DO SOLO E CONDIÇÕES AMBIENTAIS NA TEMPERATURA DO SOLO E NO CULTIVO DE MORANGUEIRO EM AMBIENTE PROTEGIDO E A CÉU ABERTO ${ }^{1}$
}

\author{
REGINA C. DE M. PIRES ${ }^{2}$, MARCOS V. FOLEGATTI ${ }^{3}$, MÁRIO J. PEDRO JÚNIOR ${ }^{4}$, \\ EMÍlIO SAKAI ${ }^{3}$, FRANCISCO A. PASSOS ${ }^{5}$, FLÁVIO B. ARRUDA ${ }^{3}$, \\ RINALDO DE O. CALHEIROS ${ }^{3}$
}

\begin{abstract}
RESUMO: A temperatura do solo é um importante parâmetro no cultivo do morangueiro, pois interfere no desenvolvimento vegetativo, na sanidade e na produção. $\mathrm{O}$ objetivo do presente trabalho foi avaliar o efeito de diferentes níveis de água, coberturas de canteiro em campo aberto e em ambiente protegido, na temperatura máxima do solo no cultivo do morangueiro. Foram realizados dois experimentos: um em cultivo protegido e outro a campo aberto, em Atibaia - SP, em esquema fatorial $2 \times 3$ (coberturas do solo e níveis de irrigação), em blocos ao acaso, com cinco repetições. As coberturas de solo utilizadas foram filmes de polietileno preto e transparente. A irrigação localizada foi aplicada por gotejo sempre que o potencial de água no solo atingisse - $0,010\left(\mathrm{~N}_{1}\right),-0,035\left(\mathrm{~N}_{2}\right)$ e $-0,070$ $\left(\mathrm{N}_{3}\right) \mathrm{MPa}$, em tensiômetros instalados a $10 \mathrm{~cm}$ de profundidade. A temperatura do solo foi avaliada por termógrafos, sendo os sensores instalados a $5 \mathrm{~cm}$ de profundidade. Houve influência do ambiente de cultivo, da cobertura do solo e dos níveis de irrigação na temperatura máxima do solo. A temperatura do solo sob diferentes coberturas dependeu não somente das características físicas do plástico, como também da forma de instalação no canteiro. A temperatura máxima do solo aumentou com a diminuição do potencial da água no solo, no momento da irrigação.
\end{abstract}

PALAVRAS-CHAVE: irrigação, cobertura de solo, morango.

\section{EFFECT OF WATER LEVELS, SOIL COVERS AND ENVIRONMENT IN MAXIMUM SOIL TEMPERATURE IN STRAWBERRY CROP IN FIELD AND GREENHOUSE}

SUMMARY: The soil temperature is an important parameter in strawberry crop, because, it interferes in vegetative development, plant health conditions and yield. The aim of this work was to evaluate the effect of different water levels, soil covers in field conditions and greenhouse in maximum soil temperature in strawberry crop. Two experiments were accomplished, one in greenhouse and other in field conditions, at Atibaia - SP, Brazil. The experimental design was a factorial 2 × 3 (soil covers and water levels), with 5 repetitions. The soil covers were clear and black plastics. The trickle irrigation was applied whenever the soil water potential reached $-0.010,-0.035$ or $-0.070 \mathrm{MPa}$ at a depth of 10 $\mathrm{cm}$. The soil temperature was evaluated by thermographs. The sensors was installed at a depth of $5 \mathrm{~cm}$. There were influence of environment cultivation, soil covers and water levels in the maximum soil temperature. The soil temperature under different soil covers depended not only of the plastic physical characteristics as well as the installation procedure. The maximum soil temperature increased as soil water potential reduced at time of irrigation.

KEYWORDS: irrigation, mulching, strawberry.

\footnotetext{
${ }^{1}$ Extraído da tese de Doutorado da primeira autora, apresentada à Escola Superior de Agricultura "Luiz de Queiroz", USP.

${ }^{2}$ Eng $^{\mathrm{a}}$ Agrônoma, Dra., Pesquisadora Científica, Centro de Pesquisa e Desenvolvimento de Ecofisiologia e Biofísica, Instituto Agronômico (IAC), APTA, Campinas - SP, Fone: (0XX19) 32415188 R: 351, e-mail: rcmpires@iac.sp.gov.br.

${ }^{3}$ Eng $^{\mathrm{o}}$ Agrônomo, Prof. Dr., Departamento de Engenharia Rural, ESALQ/USP, Piracicaba - SP.

${ }^{4}$ Eng ${ }^{\circ}$ Agrônomo, Pesquisador Científico, Dr., Centro de Pesquisa e Desenvolvimento de Ecofisiologia e Biofísica, Instituto Agronômico - IAC, Campinas - SP.

${ }^{5}$ Eng ${ }^{\mathrm{o}}$ Agrônomo, Pesquisador Científico, Dr., Centro de Horticultura, Instituto Agronômico (IAC), Campinas - SP.

Recebido pelo Conselho Editorial em: 3-6-2003
}

Aprovado pelo Conselho Editorial em: 25-10-2004 


\section{INTRODUÇÃO}

A temperatura do solo tem grande importância no cultivo do morangueiro, pois pode interferir no desenvolvimento vegetativo, na sanidade e na produção da cultura (MAAS, 1998; SMITH \& BLACK, 1987; GALLETTA \& BRINGHURST, 1990).

GALLETTA \& BRINGHURST (1990) relataram que o crescimento da planta diminuiu quando ocorreram valores extremos de temperatura do solo, sendo satisfatório na faixa de 12,8 a $29,4{ }^{\circ} \mathrm{C}$, para a cv. Shasta, e de 7,2 a $29,4{ }^{\circ} \mathrm{C}$, para a cv Lassen. Em média, o crescimento da planta foi otimizado quando a temperatura do solo foi de $23,9^{\circ} \mathrm{C}$. A produção de frutos foi maximizada por temperaturas do solo na faixa de 7,2 a $12,8^{\circ} \mathrm{C}$. Vários autores têm observado variação da temperatura do solo, comparando cultivo em campo aberto e em ambiente protegido. SCHNEIDER et al. (1993) observaram que, no interior da estufa, os valores de temperatura do solo foram sempre maiores em relação aos do ambiente externo. Por outro lado, PASSOS (1997) observou que a temperatura do solo não foi afetada pelo ambiente no cultivo do morangueiro; no entanto, a ausência de diferenças entre esses valores pode ter sido conseqüência do manejo das cortinas que ficaram levantadas durante a maior parte do período, além do fato de as estufas serem estreitas e não possuírem proteção lateral.

No cultivo do morangueiro, a adoção de cobertura de canteiro e de irrigação consiste em práticas fundamentais para obtenção de elevadas produtividades (PASSOS, 1997). As coberturas de solo e o manejo das irrigações afetam o microclima do solo pela alteração no saldo de radiação da superfície e por evitar a evaporação de água do solo (LIAKATAS et al., 1986). Tais fatores podem afetar a temperatura e a umidade do solo na zona das raízes e, conseqüentemente, o desenvolvimento vegetativo e a produtividade das plantas. Por essas razões, a temperatura do solo é um parâmetro importante para comparar o efeito de diferentes práticas no cultivo do morangueiro, tais como: coberturas de canteiro, irrigação e ambientes de cultivo. Dentre as coberturas de canteiro, o plástico preto é o mais utilizado no cultivo do morangueiro no Estado de São Paulo (GROPPO \& TESSARIOLI NETO, 1991), e o transparente tem sido utilizado com sucesso para várias cultivares e locais no mundo (VOTH, 1972; VOTH \& BRINGHURST, 1990). Alguns resultados de pesquisa mostraram valores maiores da temperatura do solo sob polietileno transparente (VOTH, 1972; VOTH \& BRINGHURST, 1990; GUPTA \& ACHARYA, 1993; HIMELRICK et al., 1993) comparado ao preto. Entretanto, LIAKATAS et al. (1986) e HAM et al. (1993) salientam que, além das características físicas do material utilizado, a metodologia de aplicação da cobertura pode interferir no comportamento térmico do solo, e com isso alguns resultados são contraditórios.

A irrigação é uma prática essencial para o cultivo do morangueiro, entretanto o excesso de água aplicada, bem como o modo de aplicação podem propiciar condições favoráveis ao desenvolvimento de doenças de difícil controle, que levam à queda na produtividade da cultura (MAAS, 1998). McNIESH et al. (1985), entre outros, salientam que o morangueiro é sensível ao déficit e ao excesso de água, ressaltando a importância do manejo da irrigação.

No Brasil, tradicionalmente, cultiva-se o morango a campo aberto, enquanto em algumas regiões do mundo o cultivo protegido tem sido utilizado com a finalidade de proteção contra os rigores climáticos e melhor controle de doenças. Na região de Atibaia - SP, no início da década de 1990, o cultivo protegido, aliado à irrigação por gotejamento, foi introduzido como tentativa de controle da antracnose em flores e frutos jovens no morangueiro (PASSOS, 1997).

O presente trabalho teve como objetivo avaliar o efeito de diferentes níveis de água, coberturas de solo em campo aberto e em ambiente protegido na temperatura máxima do solo, no cultivo do morangueiro. 


\section{MATERIAL E MÉTODOS}

Foram realizados dois experimentos com morangueiro, um em cultivo protegido e outro a céu aberto, em Atibaia - SP. O clima da região é do tipo Cfa, segundo a classificação de Köeppen, sendo subtropical de altitude, com verão quente (temperatura média do mês mais quente acima de $22{ }^{\circ} \mathrm{C}$ ), sem estação seca pronunciada.

Os experimentos foram iniciados em 20-4-1995, com o transplantio das mudas, e finalizados em 22-12 do mesmo ano, com a última colheita de frutos. A cultivar utilizada foi a Campinas IAC 2712. O solo foi classificado como Latossolo Vermelho-Amarelo, textura argilosa, sendo desinfestado com Bromex antes do plantio, com o objetivo de controlar plantas invasoras e fungos patogênicos de solo, uma vez que a área já havia sido cultivada com morangueiro em anos anteriores (LARSON \& SHAW, 1995).

Os experimentos foram implantados em esquema fatorial $2 \times 3$ (coberturas do solo e níveis de irrigação), em blocos ao acaso, com cinco repetições, totalizando 30 parcelas em cada ambiente. Um dos experimentos foi instalado a céu aberto, como é normalmente cultivado o morangueiro no Brasil, e o outro em ambiente protegido. As parcelas constaram de canteiros de 5,1 m de comprimento e 1,2 m de largura, sendo as plantas cultivadas no espaçamento de $0,30 \times 0,30 \mathrm{~m}$, totalizando 68 plantas em cada parcela.

O experimento em cultivo protegido foi conduzido em estufa modelo capela, com estrutura de madeira, com $7 \mathrm{~m}$ de largura e $50 \mathrm{~m}$ de comprimento, coberta com filme de polietileno de baixa densidade, transparente, com espessura de 100 micra. O maior lado da estufa ficou orientado na direção noroeste-sudeste. A altura máxima da estufa no centro foi de $3,0 \mathrm{~m}$ e nas laterais $2,15 \mathrm{~m}$. As laterais da estufa foram protegidas para evitar entrada de água por escoamento superficial ou por movimento lateral de água no solo, com filme de polietileno transparente desde $0,70 \mathrm{~m}$ de profundidade no solo até $0,75 \mathrm{~m}$ de altura. $\mathrm{O}$ restante relativo a altura das laterais da estufa $(1,40 \mathrm{~m})$ permaneceu totalmente aberto durante os dias, sem ocorrência de precipitação. Em caso de chuva, as cortinas eram fechadas. As parcelas foram instaladas paralelamente ao maior lado da estufa.

As coberturas de solo utilizadas foram os filmes de polietileno de baixa densidade (PEBD), preto e transparente. O plástico preto (PP) tinha espessura de 30 micra, sendo que o plástico transparente (PT) utilizado no cultivo protegido tinha 50 micra de espessura e no campo aberto 150 micra. Devido à escassez de filme de polietileno transparente (PT) de 50 micra, no local da experimentação, utilizaramse filmes de espessuras diferentes nos experimentos. No experimento a campo aberto, as coberturas de solo foram instaladas em maio, e no cultivo protegido no início de junho.

Para controlar os níveis de irrigação, foram utilizados tensiômetros com vacuômetro de mercúrio, sendo a sensibilidade de leitura a cada milímetro de altura da coluna de mercúrio. Até o início dos tratamentos de níveis de água, as irrigações foram realizadas sempre que o potencial de água no solo atingia - $0,01 \mathrm{MPa}$ no tensiômetro instalado a $10 \mathrm{~cm}$ de profundidade. Na fase de pegamento das mudas, as irrigações foram realizadas por aspersão, parceladas de duas a seis vezes ao dia. $\mathrm{O}$ sistema de irrigação por gotejamento foi instalado em maio com emissores a cada $0,3 \mathrm{~m}$, em cada um dos canteiros, sendo os níveis de água diferenciados a partir de junho. Foram colocadas duas linhas de gotejadores sobre cada canteiro, com quatro fileiras de plantas, sendo cada linha entre duas fileiras de plantas, exceto a central. Utilizaram-se três níveis de potencial de água no solo para a determinação do momento das irrigações, correspondendo a -0,010 $\left(\mathrm{N}_{1}\right),-0,035\left(\mathrm{~N}_{2}\right)$ e - $-0,070\left(\mathrm{~N}_{3}\right)$ MPa, medidos em tensiômetros instalados a $10 \mathrm{~cm}$ de profundidade. Em cada combinação de cobertura do solo e nível de irrigação, foram instaladas três estações tensiométricas, sendo duas delas com tensiômetros a 10 e a 20 $\mathrm{cm}$ de profundidade, e uma terceira com cinco tensiômetros instalados nas profundidades de 10; 20; 
30; 40 e $50 \mathrm{~cm}$. Os tensiômetros instalados de 20 a $50 \mathrm{~cm}$ de profundidade tiveram a função de monitorar a frente de molhamento no perfil do solo e auxiliar o ajuste das lâminas de irrigação.

Para a determinação da temperatura do solo, sob as duas coberturas plásticas, nos diferentes níveis de água no solo, foram instalados termógrafos, marca Foxboro, com precisão de $0,2{ }^{\circ} \mathrm{C}$, nos dois experimentos, sem repetição. Os sensores foram instalados a $5 \mathrm{~cm}$ de profundidade, entre as linhas centrais de plantas nas parcelas. Foram determinadas as temperaturas do solo máximas diárias, ocorridas em períodos variáveis, conforme a disponibilidade dos dados, uma vez que houve problemas funcionais dos equipamentos. Os dados de temperatura máxima do solo nos diferentes tratamentos foram submetidos à análise de intervalos de confiança, conforme SNEDECOR \& COCHRAN (1973), utilizando o Teste $\mathrm{t}$, a $5 \%$ de probabilidade.

Em abrigos meteorológicos localizados a aproximadamente $15 \mathrm{~m}$ de distância do experimento a campo aberto, e no centro da estufa, no cultivo protegido, foram instalados para a medição da temperatura do ar termoigrógrafos, marca R. Fuess, com precisão de $0,5^{\circ} \mathrm{C}$. No campo, também foram instalados pluviômetro e tanque Classe A. As médias das temperaturas máximas, mínimas e médias do ar ocorridas nos dois experimentos, e da evaporação no tanque Classe A (ECA) e os totais de precipitação por período foram agrupados em períodos de 10 a 11 dias e encontram-se nas Tabelas $1 \mathrm{e}$ 2 , para o cultivo protegido e campo aberto, respectivamente.

TABELA 1. Valores médios de temperatura máxima, mínima e média do ar, ocorridos no período de 19-5 a 22-12-1995, sob cultivo protegido, em Atibaia - SP.

\begin{tabular}{|c|c|c|c|}
\hline \multirow{2}{*}{ Período } & \multicolumn{3}{|c|}{ Temperatura $\left({ }^{\circ} \mathrm{C}\right)$} \\
\hline & Máxima & Mínima & Média* \\
\hline 19 a $31-5$ & 22,7 & 9,9 & 15,5 \\
\hline $1^{\circ}$ a $10-6$ & 24,8 & 7,3 & 14,4 \\
\hline 11 a $20-6$ & 22,9 & 8,9 & 14,6 \\
\hline 21 a $30-6$ & 23,6 & 11,4 & 16,3 \\
\hline $1^{\mathrm{o}}$ a $10-7$ & 23,4 & 11,6 & 16,5 \\
\hline 11 a $20-7$ & 26,7 & 11,4 & 17,5 \\
\hline 21 a $31-7$ & 27,7 & 10,6 & 17,6 \\
\hline $1^{\mathrm{o}}$ a $10-8$ & 26,5 & 11,8 & 17,5 \\
\hline 11 a $20-8$ & 28,6 & 11,8 & 18,7 \\
\hline 21 a $31-8$ & 30,8 & 10,5 & 19,5 \\
\hline $1^{\mathrm{o}}$ a $10-9$ & 28,7 & 9,7 & 18,1 \\
\hline 11 a $20-9$ & 26,3 & 13,1 & 18,4 \\
\hline 21 a $30-9$ & 25,7 & 15,0 & 19,0 \\
\hline $1^{\mathrm{o}}$ a $10-10$ & 28,9 & 14,6 & 20,3 \\
\hline 11 a $20-10$ & 25,3 & 14,1 & 20,9 \\
\hline 21 a $31-10$ & 27,9 & 11,8 & 19,8 \\
\hline $1^{\circ}$ a $10-11$ & 30,9 & 15,2 & 21,9 \\
\hline 11 a $20-11$ & 26,7 & 14,9 & 20,1 \\
\hline 21 a $30-11$ & 29,4 & 14,4 & 20,3 \\
\hline $1^{\circ}$ a $10-12$ & 29,8 & 15,2 & 21,3 \\
\hline 11 a $22-12$ & 28,4 & 16.8 & 21.4 \\
\hline
\end{tabular}

* Valores diários estimados pela média das leituras obtidas a cada duas horas. 
TABELA 2. Valores médios de temperatura máxima, mínima e média do ar e evaporação de tanque Classe A, ECA, e totais de precipitação, ocorridos desde 20-4 até 22-12-1995, no cultivo a campo aberto, em Atibaia - SP.

\begin{tabular}{|c|c|c|c|c|c|}
\hline \multirow{2}{*}{ Período } & \multicolumn{3}{|c|}{ Temperatura $\left({ }^{\circ} \mathrm{C}\right)$} & $\overline{\text { ECA }}$ & \multirow{2}{*}{ Precipitação } \\
\hline & Máxima & Mínima & Média * & ------- & \\
\hline 20 а $30-4$ & --- & --- & --- & --- & 6,2 \\
\hline $1^{\circ}$ a $10-5$ & --- & --- & --- & --- & 44,0 \\
\hline 11 a $20-5$ & --- & --- & --- & --- & 0 \\
\hline 21 a $31-5$ & 22,3 & 11,0 & 16,0 & --- & 0 \\
\hline $1^{\circ}$ a $10-6$ & 24,6 & 9,2 & 16,1 & --- & 0 \\
\hline 11 a $20-6$ & 23,4 & 11,2 & 16,5 & --- & 28,1 \\
\hline 21 a $30-6$ & 22,0 & 11,6 & 15,9 & --- & 20,4 \\
\hline $1^{\mathrm{o}}$ a $10-7$ & 22,1 & 12,1 & 16,5 & 3,5 & 66,6 \\
\hline 11 a $20-7$ & 24,6 & 11,6 & 16,9 & 3,4 & 0 \\
\hline 21 a $31-7$ & 26,2 & 10,6 & 17,8 & 4,5 & 25,0 \\
\hline $1^{\mathrm{o}}$ a $10-8$ & 25,3 & 11,6 & 17,8 & 4,6 & 7,6 \\
\hline 11 a $20-8$ & 27,4 & 12,6 & 19,3 & 4,4 & 0 \\
\hline 21 a $31-8$ & 29,5 & 10,7 & 19,6 & 4,0 & 0 \\
\hline $1^{\mathrm{o}}$ a $10-9$ & 27,2 & 10,0 & 18,0 & 4,4 & 0 \\
\hline 11 a $20-9$ & 25,6 & 13,6 & 18,8 & 4,3 & 10,4 \\
\hline 21 a $30-9$ & 23,6 & 14,5 & 18,3 & 4,0 & 77,4 \\
\hline $1^{\circ}$ a $10-10$ & 28,5 & 15,8 & 20,8 & 3,7 & 8,0 \\
\hline 11 a $20-10$ & 24,2 & 15,4 & 19,1 & 4,5 & 176,4 \\
\hline 21 a $31-10$ & 27,0 & 13,3 & 21,7 & 5,2 & 81,4 \\
\hline $1^{\circ}$ a $10-11$ & 29,7 & 16,9 & 23,0 & 3,6 & 8,0 \\
\hline 11 a $20-11$ & 26,0 & 16,3 & 20,3 & 5,4 & 24,6 \\
\hline 21 a $30-11$ & 28,1 & 15,1 & 20,0 & 4,5 & 46,6 \\
\hline $1^{\mathrm{o}}$ a $10-12$ & 28,8 & 16,2 & 21,6 & 5,4 & 21,8 \\
\hline 11 a $22-12$ & 27,8 & 17,4 & 22,0 & 5,1 & 111,0 \\
\hline Total & & & & & 763,5 \\
\hline
\end{tabular}

* Valores diários estimados pela média das leituras obtidas a cada duas horas.

\section{RESULTADOS E DISCUSSÃO}

Nas Figuras 1 a 4, são apresentados os valores diários de temperatura máxima do solo, a $5 \mathrm{~cm}$ de profundidade, ocorridos nas diferentes coberturas do solo e níveis de água, no cultivo protegido e a campo aberto.

Comparando-se os intervalos de confiança das médias das temperaturas máximas do solo, a 5\% de probabilidade, observa-se que, no cultivo protegido, a temperatura sob plástico transparente foi significativamente menor que a ocorrida no plástico preto, nos níveis de água de -0,035 e -0,070 MPa (Figura 1B e 1C). Quando o teor de água no solo foi mantido mais elevado (nível de água de $-0,010 \mathrm{MPa}$ ), não foi observada diferença estatística (Figura 1A). Por outro lado, no cultivo a campo aberto, a média das temperaturas máximas do solo sob plástico transparente foi maior que no plástico preto, em todos os níveis de água (Figura 3). Nesse caso, foram observadas diferenças significativas entre a temperatura máxima do solo, ocorrida sob as duas coberturas, independentemente do nível de irrigação e da ocorrência ou não de chuvas. 

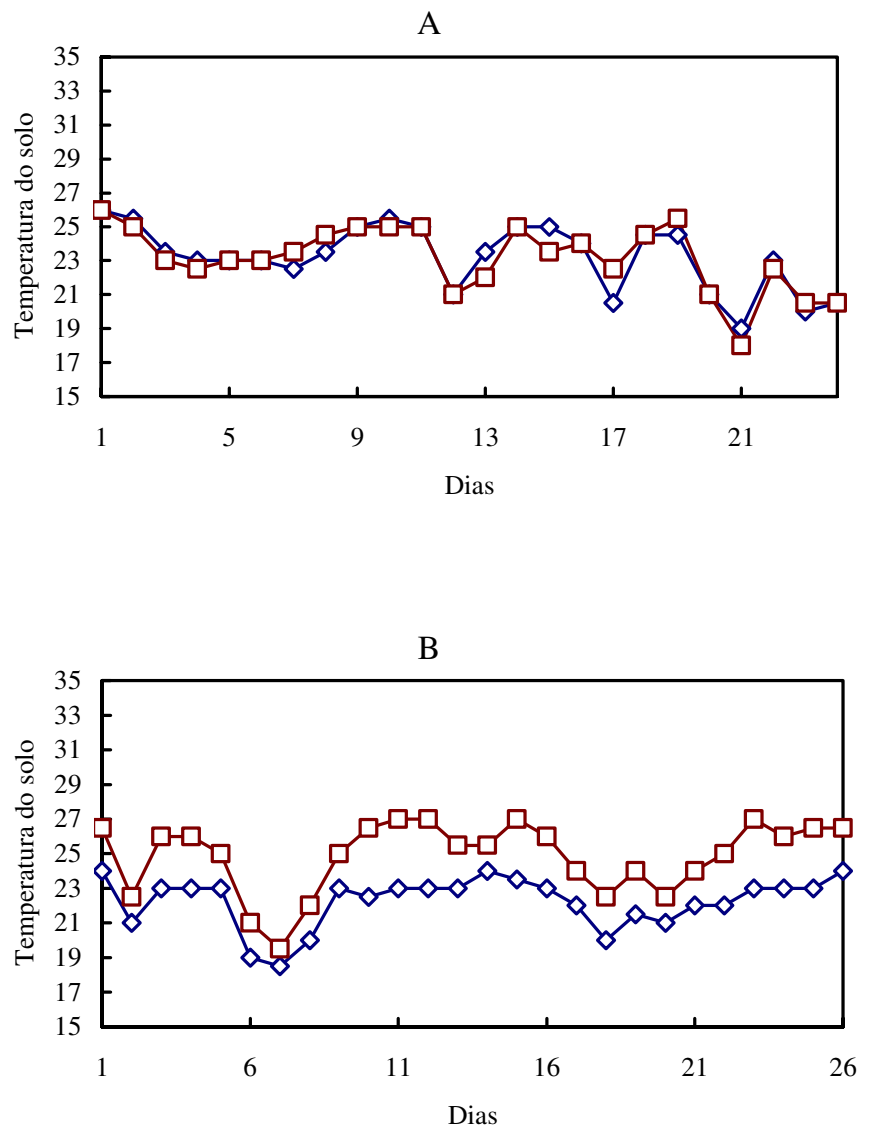

$\mathrm{C}$

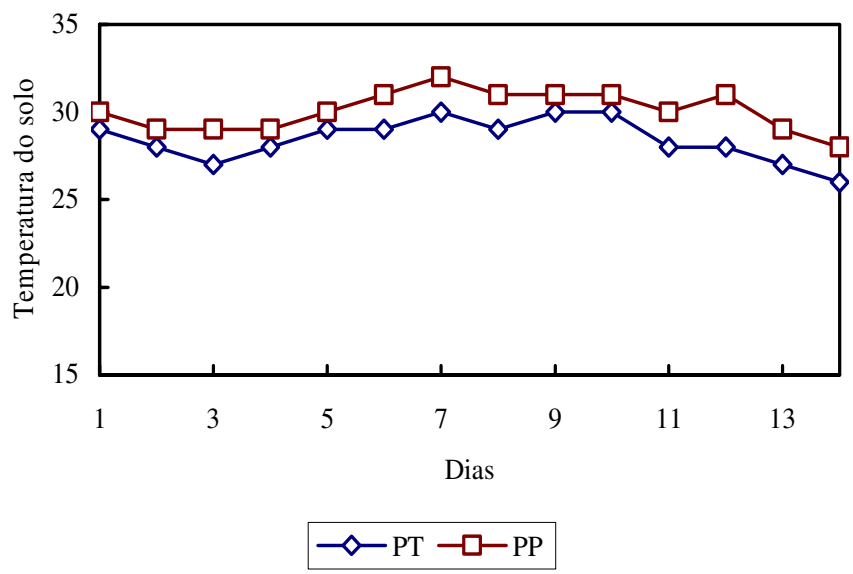

FIGURA 1. Temperatura máxima diária do solo $\left({ }^{\circ} \mathrm{C}\right)$ a $5 \mathrm{~cm}$ de profundidade, sob plástico transparente (PT) e plástico preto (PP). As Figuras A, B e C referem-se aos níveis de água de $-0,010 \mathrm{MPa}(1$ a 24-9), $-0,035 \mathrm{MPa}(3$ a 28-7) e $-0,070 \mathrm{MPa}$ (21-8 a 3-9), respectivamente, no morangueiro em cultivo protegido.

Com relação à influência dos níveis de água na temperatura do solo, no cultivo protegido, observou-se tendência de diminuição de temperatura nos tratamentos mais úmidos (Figura 2). 
Utilizando-se do plástico transparente (Figura 2A), foram observadas diferenças significativas entre a temperatura do solo, no nível de água de -0,070 MPa e os demais (-0,035 e -0,010 MPa). Em média, a temperatura máxima no nível de água de $-0,070$ foi $3,9^{\circ} \mathrm{C}$ e $5,3^{\circ} \mathrm{C}$ maior em relação aos valores observados nos níveis de irrigação de $-0,035$ e $-0,010 \mathrm{MPa}$, respectivamente. Porém, entre os dois últimos, a diferença não foi significativa. Por outro lado, sob plástico preto (Figura 2B), ocorreram diferenças significativas entre os três níveis de água estudados. A temperatura máxima do solo foi decrescente com o aumento da umidade do solo, como era de se esperar, pela alta capacidade calorífica da água. No nível mais seco $(-0,070 \mathrm{MPa})$, observaram-se temperaturas médias acima dos demais da ordem de $3,0^{\circ} \mathrm{C}(-0,035 \mathrm{MPa})$ e $4,8^{\circ} \mathrm{C}(-0,010 \mathrm{MPa})$. Entre os níveis de água de $-0,010 \mathrm{e}$ $-0,035 \mathrm{MPa}$, a diferença média foi de $1,8^{\circ} \mathrm{C}$ a favor do nível intermediário (-0,035 MPa).

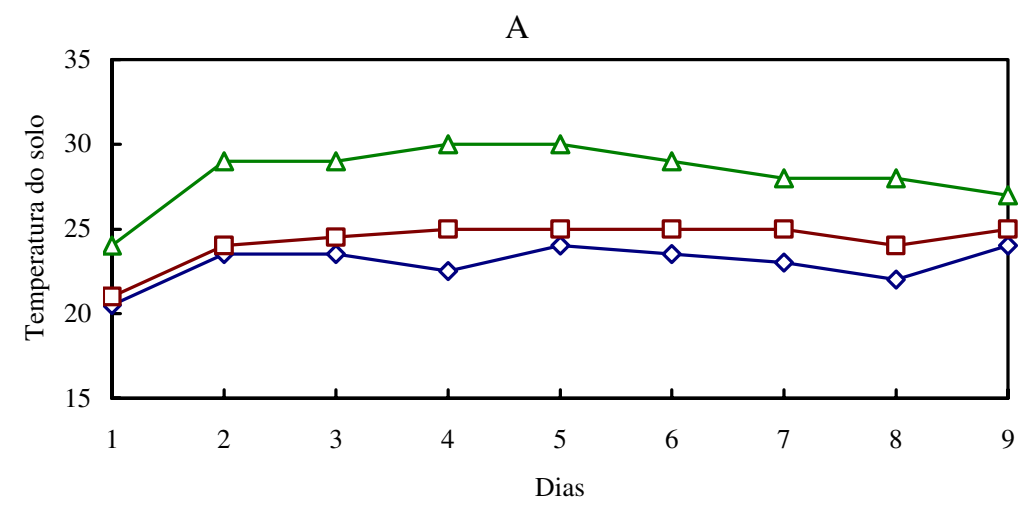

B

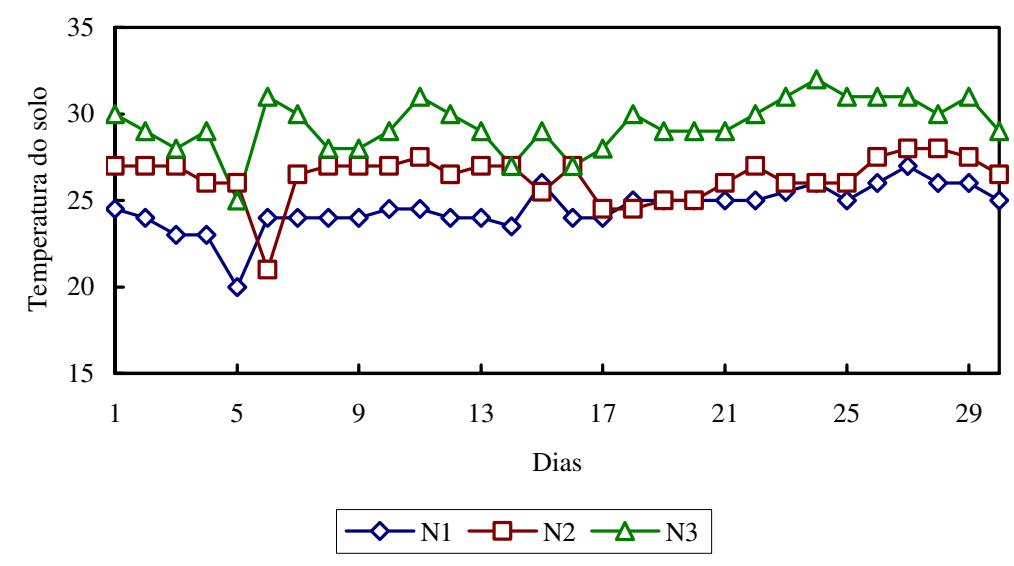

FIGURA 2. Valores diários de temperatura máxima do solo $\left({ }^{\circ} \mathrm{C}\right)$ a $5 \mathrm{~cm}$ de profundidade, sob plástico transparente (A), no período de $1^{\circ}$ a $9-6$ e sob plástico preto (B), no período de $1^{0}$ a $30-8$, nos três níveis de água $-0,010(\mathrm{~N} 1),-0,035(\mathrm{~N} 2)$ e $-0,070 \mathrm{MPa}(\mathrm{N} 3)$, no morangueiro em cultivo protegido. 
A

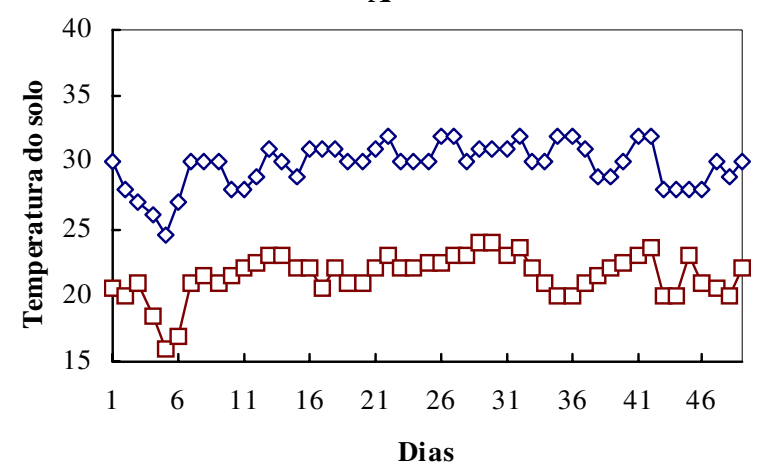

B

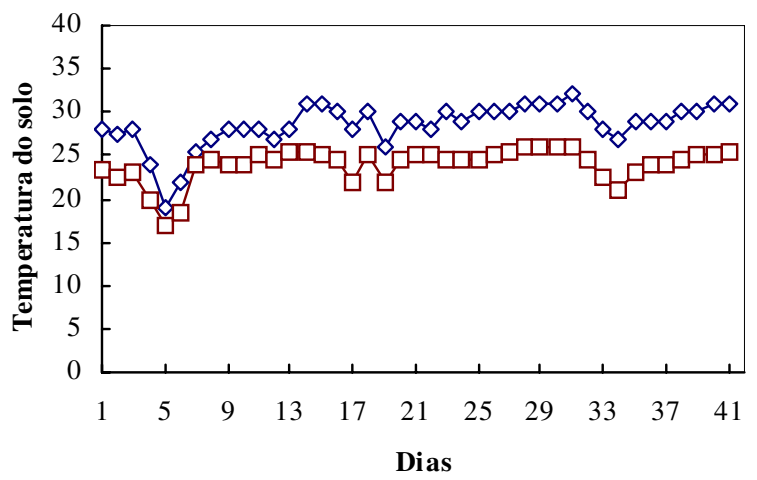

C

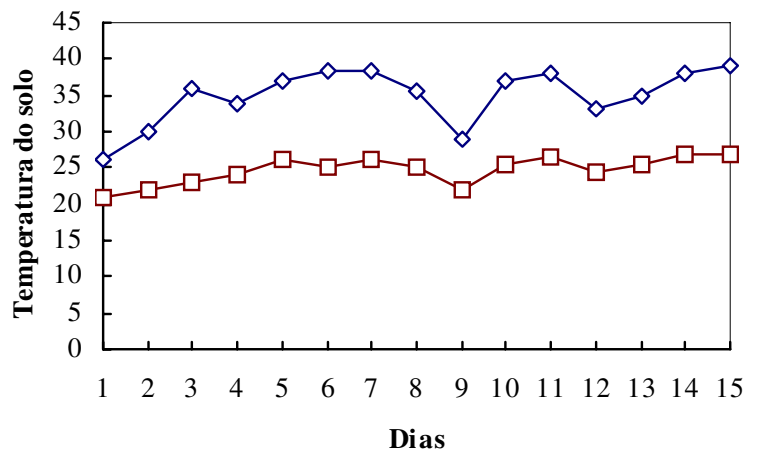

$\diamond-\mathrm{PT} \multimap-\mathrm{PP}$

FIGURA 3. Temperatura máxima diária do solo $\left({ }^{\circ} \mathrm{C}\right)$ a $5 \mathrm{~cm}$ de profundidade, sob plástico transparente (PT) e plástico preto (PP). As Figuras $\mathrm{A}, \mathrm{B}$ e $\mathrm{C}$ referem-se aos níveis de água de $-0,010 \mathrm{MPa}(1-8$ a 18-9), -0,035 MPa (1-8 a 10-9) e -0,070 MPa (28-9 a 12-10), respectivamente, no morangueiro em campo aberto

No cultivo a campo aberto, os valores de temperatura do solo, nos diferentes níveis, foram apresentados em períodos chuvosos e secos, ou com pouca chuva (Figura 4). Não ocorreram diferenças significativas nos valores de temperatura do solo, medidos entre os níveis de água nos períodos chuvosos, para as duas coberturas do solo (Figura 4B e 4C). Sob plástico transparente, em períodos de pouca chuva (Figura 4A), a temperatura máxima do solo diferiu significativamente nos três níveis de água estudados. As maiores temperaturas máximas foram observadas no nível de - 
0,070 $\mathrm{MPa}$, com diferenças médias no período de $2,6^{\circ} \mathrm{C}$ e $4,1^{\circ} \mathrm{C}$ em relação aos níveis de água de 0,010 e -0,035 $\mathrm{MPa}$, respectivamente. No cultivo com plástico preto, foi observado, em período sem ocorrência de precipitações (Figura 4D), que a temperatura do solo foi menor no nível de -0,010 MPa, diferindo significativamente dos demais níveis. Em média, essas diferenças foram de $2,8{ }^{\circ} \mathrm{C}$ e $1,8{ }^{\circ} \mathrm{C}$ em relação aos níveis $-0,035$ e -0,070 $\mathrm{MPa}$, respectivamente. Entre os níveis de -0,035 e -0,070 MPa, não houve diferença significativa.
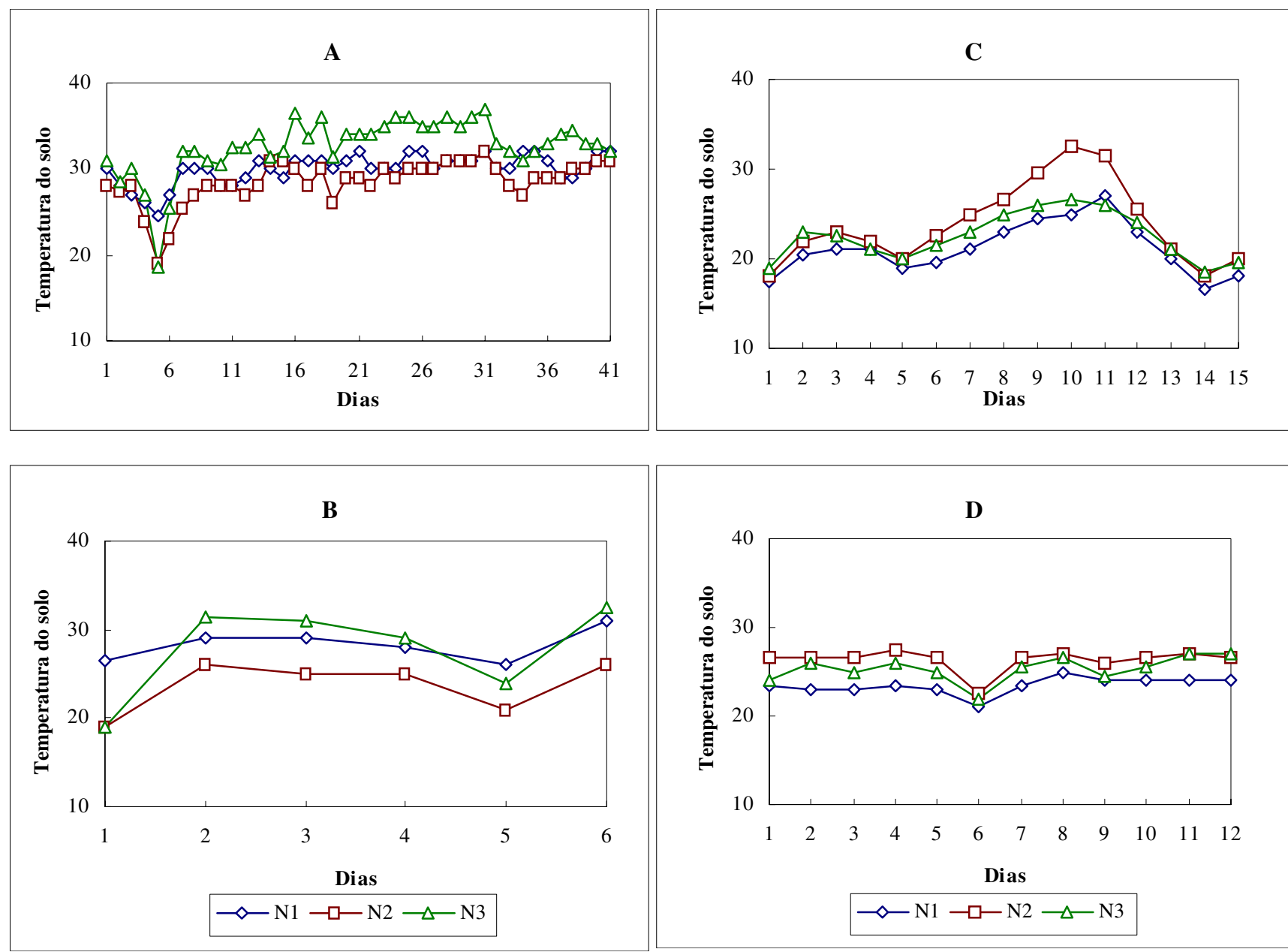

FIGURA 4. Valores diários de temperatura máxima do solo $\left({ }^{\circ} \mathrm{C}\right)$ a $5 \mathrm{~cm}$ de profundidade, sob plástico transparente, nos períodos de $1^{\underline{0}}-8$ a 10-9 (A) (período com pouca chuva) e de 17 a $22-$ 10 (B) (período chuvoso); e sob plástico preto nos períodos de 17 a 31-10 (C) (período chuvoso) e de $1^{\circ}$ a $12-10$ (D) (período sem chuva), nos três níveis de água -0,010 (N1), $-0,035(\mathrm{~N} 2)$ e $-0,070 \mathrm{MPa}(\mathrm{N} 3)$, no morangueiro cultivado a campo aberto.

Na Figura 5, são apresentados os valores de temperatura máxima do solo, desde $1^{\underline{0}}-8$ até 23-9, no nível de irrigação de $-0,010 \mathrm{MPa}$, sob os plásticos transparente e preto, nos dois ambientes de cultivo. Nota-se que as temperaturas máximas sob plástico transparente foram maiores no cultivo a campo aberto, quando comparadas ao cultivo protegido, com diferença máxima de $9{ }^{\circ} \mathrm{C}$, e média no período de $5,9^{\circ} \mathrm{C}$. No entanto, cabe ressaltar que havia diferença na espessura dos plásticos transparentes utilizados nos experimentos, sendo o mais espesso no cultivo a campo aberto. Sob plástico preto, observou-se que, no cultivo protegido, a temperatura máxima do solo atingiu valores maiores que os observados a campo aberto, sendo a maior diferença de $4,0^{\circ} \mathrm{C}$ e, em média, $2,2^{\circ} \mathrm{C}$, no período observado. As maiores temperaturas máximas do solo observadas no cultivo protegido, com o 
uso do plástico preto, concordam com as maiores temperaturas do ar ocorridas no ambiente protegido, comparado ao campo aberto durante o período analisado (Tabelas 1 e 2).

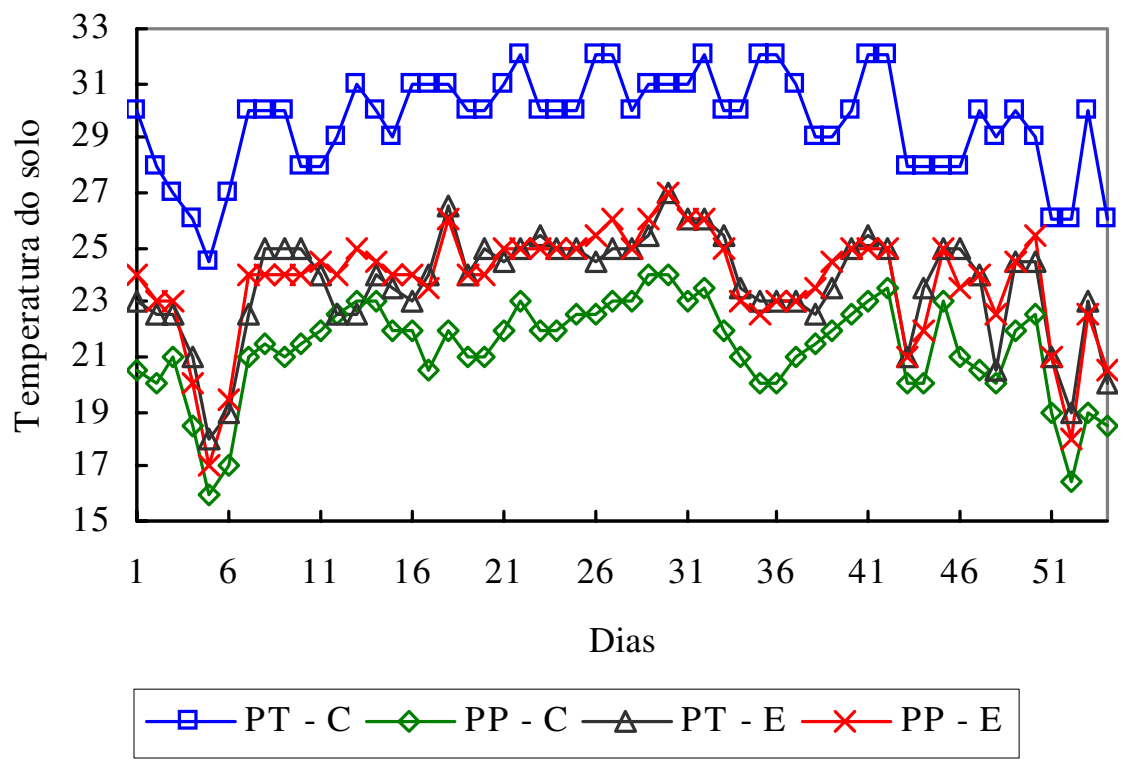

FIGURA 5. Valores diários de temperatura máxima do solo $\left({ }^{\circ} \mathrm{C}\right)$ a $5 \mathrm{~cm}$ de profundidade, sob plástico transparente (PT) e plástico preto (PP) no cultivo a campo aberto $(\mathrm{C})$ e em cultivo protegido (E), no morangueiro, no nível de irrigação de $-0,010 \mathrm{MPa}$, no período de $1^{\underline{0}}-8$ a 23-9 de 1995.

PASSOS (1997) não observou diferenças estatísticas entre a temperatura do solo sob plástico preto, ocorrida em cultivo protegido, e em condições de campo aberto, diferindo dos resultados observados no presente trabalho. No entanto, cabe ressaltar que a estufa utilizada era estreita, sem proteção lateral e mantidas as cortinas abertas.

Vários trabalhos, comparando a temperatura do solo sob diferentes coberturas, encontraram maiores valores sob o plástico transparente (VOTH \& BRINGHURST, 1990; GUPTA \& ACHARYA, 1993 e HIMELRICK et al., 1993), concordando, também, com os observados no presente estudo, no cultivo a campo aberto (Figura 3). Por outro lado, MARTINS (1983) e HAM et al. (1993) observaram temperaturas do solo maiores sob o plástico preto, comparadas ao transparente, de forma semelhante ao ocorrido no experimento no cultivo protegido (Figura 1). LIAKATAS et al. (1986) e HAM et al. (1993) ressaltaram que, devido à interferência da camada de ar existente entre a cobertura e o solo, existem muitos trabalhos com resultados contraditórios relacionados à temperatura do solo. Assim, fica evidente a interação entre o tipo de cobertura do solo e sua forma de instalação na temperatura do solo.

De acordo com os valores de temperatura do solo citados por GALLETTA \& BRINGHURST (1990), como adequados ao crescimento e produção do morangueiro para as cultivares Shasta e Lassen, observa-se que, no cultivo protegido, nos períodos avaliados, os valores foram acima dos adequados quando se utilizaram o plástico preto e o nível mais seco de irrigação (Figuras 1 e 2). Ainda com relação ao cultivo protegido, cabe ressaltar que, no plástico preto e no nível mais seco de irrigação (-0,070 MPa), nos quais ocorreram as maiores temperaturas máximas do solo, foi observada maior intensidade na ocorrência de doenças, quando comparado aos demais tratamentos. Para as condições de cultivo a campo aberto, observou-se que a adoção do plástico transparente (Figuras 3 a 5) resultou na ocorrência de valores inadequados ao cultivo do morangueiro (GALLETTA \& BRINGHURST, 
1990), diferentemente do observado por VOTH (1972), VOTH \& BRINGHURST (1990), GUPTA \& ACHARYA (1993) e HIMELRICK et al. (1993), em regiões de cultivo diferentes edafoclimaticamente daquela onde se realizou a presente experimentação.

\section{CONCLUSÕES}

Há influência do ambiente de cultivo, da cobertura do solo e dos níveis de irrigação na temperatura máxima do solo.

A temperatura do solo sob diferentes coberturas depende não somente das características físicas do plástico, como também da forma de instalação das mesmas no canteiro.

A temperatura máxima do solo diminuiu à medida que os tratamentos foram mais úmidos.

\section{REFERÊNCIAS}

GALLETTA, G.J.; BRINGHURST, R.S. Strawberry management. In: GALLETTA, G.J.; HIMELRICK, D.G. Small fruit crop management. Englewood Cliffs: Prentice Hall, 1990. p.83-156. GROPPO, G.A.; TESSARIOLI NETO, J. A cultura do morangueiro. Campinas: CATI, 1991. 16 p. (Boletim Técnico, 201).

GUPTA, R.; ACHARYA, C.L. Effect of mulch induced hydrothermal regime on root growth, water use efficiency, yield and quality of strawberry. Journal of the Indian Society of Soil Science, New Delhi, v.41, n.1, p.17-25, 1993. (Resumo em CAB Abstracts on CD-ROM, 1995).

HAM, J.M.; KLUITENBERG, G.J.; LAMONT, W.J. Optical properties of plastic mulches affect the field temperature regime. Journal of the American Society for Horticultural Science, Alexandria, v.118, n.2, p.188-93, 1993.

HIMELRICK, D.G.; DOZIER JR., W.A.; AKRIDGE, J.R. Effect of mulch type in annual hill strawberry plasticulture systems. Acta Horticulturae, Leuven, n.348, p.207-9, 1993.

LARSON, K.D.; SHAW, D.V. Relative performance of strawberry genotypes on fumigated and nonfumigated soils. Journal of the American Society for Horticultural Science, Alexandria, v.120, n.2, p.274-7, 1995.

LIAKATAS, A.; CLARK, J.A.; MONTEITH, J.L. Measurements of the heat balance under plastic mulches. Agricultural and Forest Meteorology, Amsterdam, v.36, n.3, p.227-39, 1986.

MAAS, J.L. Compendium of strawberry diseases. 2. ed. St. Paul: The American Phytopathological Society, 1998. 98 p.

MARTINS, N.L.F. Efeitos de coberturas plásticas e orgânicas sobre o rendimento de "frutos" de duas cultivares de morangueiro (Fragaria $\mathrm{x}$ ananassa Duch.) e a temperatura do solo. $1983.252 \mathrm{f}$.

Dissertação (Mestrado em Horticultura) - Faculdade de Agronomia, Universidade Federal do Rio Grande do Sul, Porto Alegre, 1983.

PASSOS, F.A. Influência de alguns sistemas de cultivo na cultura do morango (Fragaria $\mathrm{x}$ ananassa Duch.). 1997. 106 f. Tese (Doutorado em Fitotecnia) - Escola Superior de Agricultura "Luiz de Queiroz", Universidade de São Paulo, Piracicaba, 1997.

SCHNEIDER, F.M.; BURIOL, G.A.; ANDRIOLO, J.L.; ESTEFANEL, V.; STRECK, N.A. Modificação na temperatura do solo causada por estufas de polietileno transparente de baixa densidade em Santa Maria - RS. Revista Brasileira de Agrometeorologia, Santa Maria, v.1, n.1, p.37-42, 1993.

SMITH, B.J.; BLACK, L.L. Resistance of strawberry plants to Colletotrichum fragariae affected by environmental conditions. Plant Disease, St. Paul, v.71, n.9, p.834-7, 1987. 
SNEDECOR, G.W.; COCHRAN, W.G. Statistical methods. Ames: Iowa State University, 1973. $593 \mathrm{p}$.

VOTH, V. Plastics in the California strawberries. HortScience, Alexandria, v.7, n.4, p.378-80, 1972.

VOTH, V.; BRINGHURST, R.S. Culture and physiologycal manipulation of California strawberries. HortScience, Alexandria, v.25, n.8, p.889-92, 1990. 